\section{Introduction}

The low-lying Belgian coastal zone is highly populated and highly vulnerable to increased coastal flooding risks by induced climate change.

The master plan to strengthen the weak links in the coastal defence line in Belgium is established based on coastal flooding risk calculations (Mertens et al, 2010). The average climate change scenario to be expected until 2050 is an increase of surge levels of $30 \mathrm{~cm}$. The worst credible extreme scenario for the 21st century change in the North Sea climate is a mean sea level rise of $2 \mathrm{~m}$ combined with a $8 \%$ increase of extreme wind speeds (Van den Eynde et al, 2011).

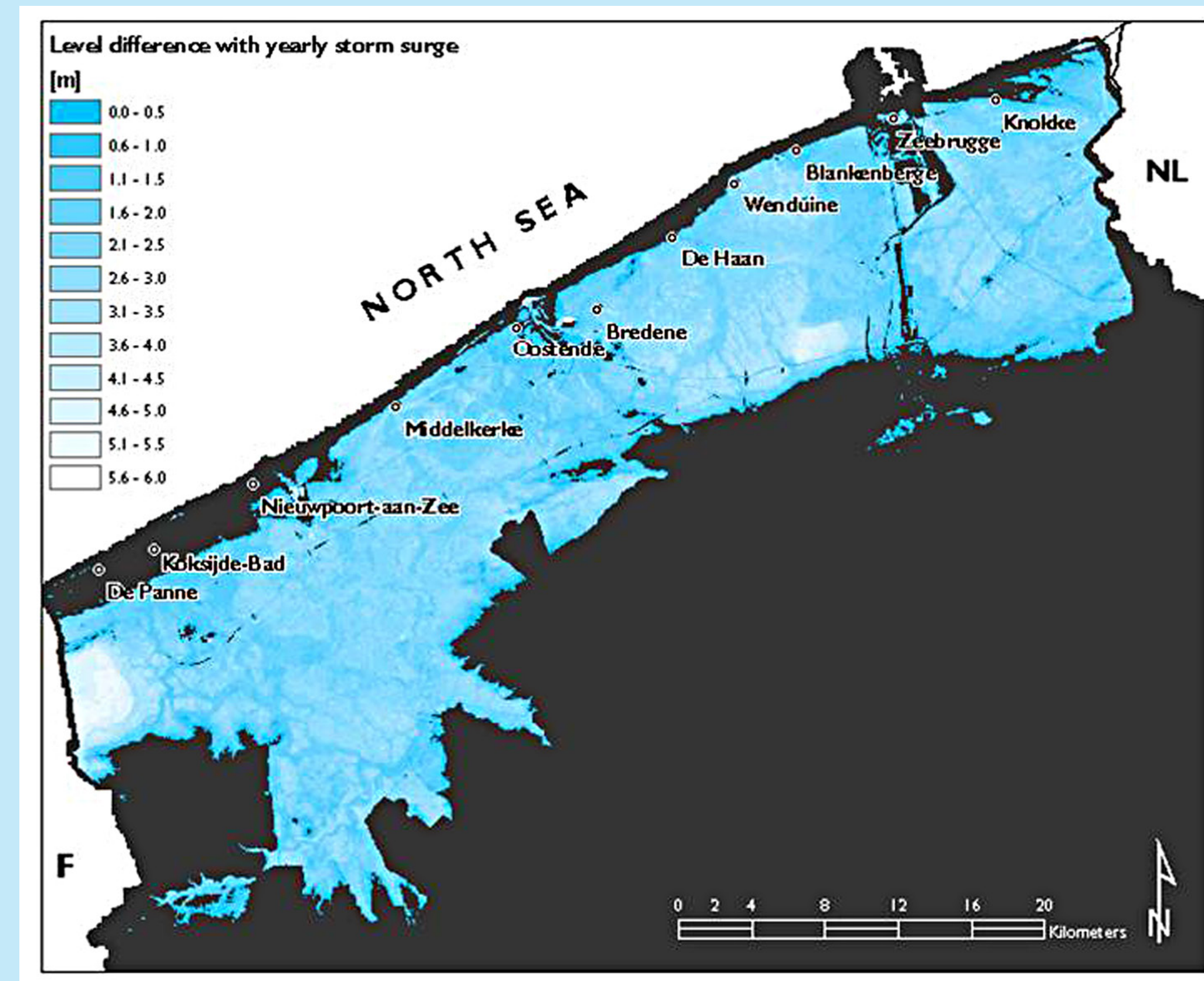

Coastal flooding risks in the Belgian coastal zone anno 2000

\begin{tabular}{c|c|c|c|}
$\begin{array}{c}\text { Storm surge height } \\
\text { (above Belgian } \\
\text { reference level "TAW") }\end{array}$ & $\begin{array}{c}\text { Return } \\
\text { period }\end{array}$ & $\begin{array}{c}\text { Human } \\
\text { deaths }\end{array}$ & $\begin{array}{c}\text { Direct } \\
\text { economic } \\
\text { damage }\end{array}$ \\
\hline$+6.5 \mathrm{~m}$ TAW & $\sim 100$ year & 41 & $€ 0.67$ billion \\
\hline$+7.0 \mathrm{~m}$ TAW & $\sim 1000$ year & 251 & $€ 2.1$ billion \\
\hline$+7.5 \mathrm{~m}$ TAW & $\sim 4000$ year & 885 & $€ 3.9$ billion \\
\hline$+8.0 \mathrm{~m}$ TAW & $\sim 17000$ year & 3297 & $€ 6.5$ billion \\
\hline
\end{tabular}

risk $=\left[\sum_{i, j, k} p_{j} \cdot p_{k} \cdot\left(\frac{w_{i}}{R_{i}}\right) \cdot S_{i, k}\right] \cdot \frac{(1+r)^{T}-1}{r T}$

\section{Adaptation of coastal protection}

Existing coastal defences in the Belgian coastal zone are relatively low-crested compared with surge levels. This fact increases the vulnerability of this coastal zone to climate change.

Different adaptation measures to manage these increasing risks were compared. Based on their effectiveness to reduce risks as well as estimates of costs for implementation it was concluded that efficient adaptation measures consist of heightening and/or widening the existing dunes, sea dikes and beaches.

Future research will investigate which adaptation measures can be developed in the coastal harbours for maintaining safety against flooding under climate change.

Toon Verwaest', Sebastian Dan, Johan Reyns ${ }^{1,3}$, Ellen Meire1, Tina Mertens², Stefaan Gysens² ${ }^{1}$ Flanders Hydraulics Research (Waterbouwkundig Laboratorium), Berchemlei 115, 2140 Antwerp, Belgium ${ }^{2}$ Agency for Maritime Services and Coast, Coast Division, Vrijhavenstraat 3, 8400 0ostende, Belgium ${ }^{3}$ Dept. of Water Engineering, UNESCO-IHE, PO Box 3015, 2601 DA Delft, The Netherlands

\title{
Coastal flooding risk and adaptation to climate change in Belgium
}

\section{Coastal flooding risk calculations}

The methodology for the coastal flooding risk calculations is based on a chain of numerical models describing characteristics of storm surges with different return periods approaching the coastal defences, the failure behaviour of these defences, the hydraulics of flooding in case of failure by breaching, overflow or overtopping of the defences and finally a GIS-based damage and casualties module adopted for use within Flanders region.

The risk was calculated for a set of four storm surges resulting in a set of damage and casualties numbers. The rate of increase of coastal flooding risks for different climate change scenarios is quantified using a simplified version of the chain of models.
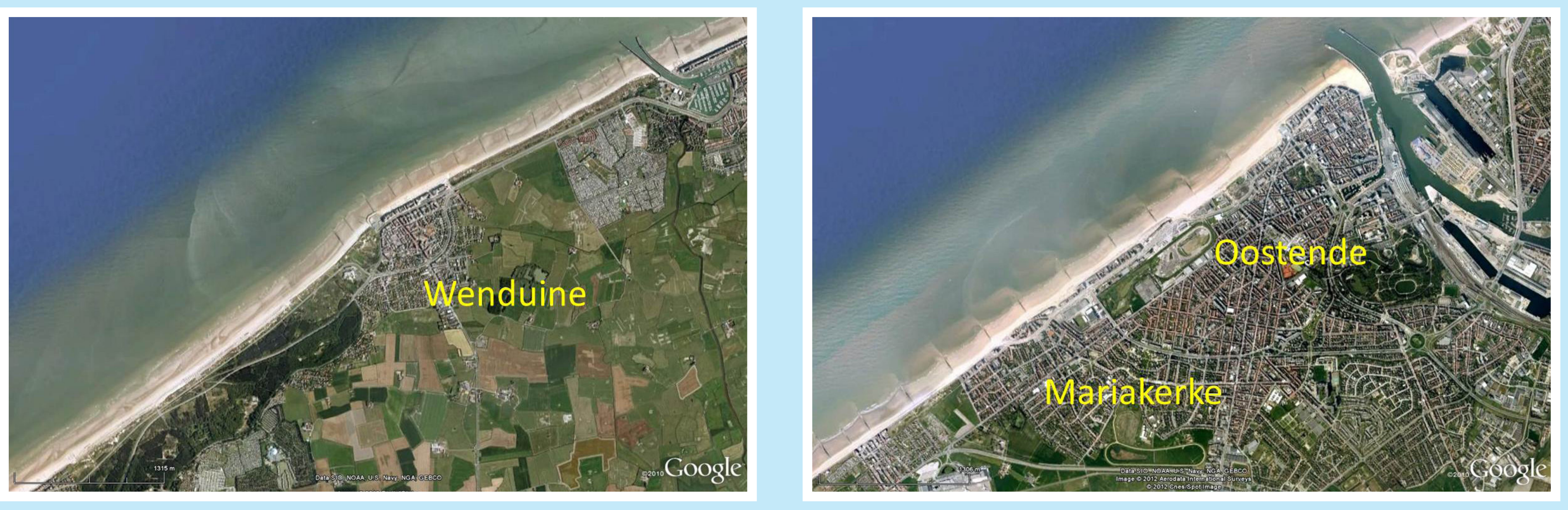

This generalised model chain was validated by comparing it with the results of the detailed model chain for the anno 2000 case. As a consequence the results on climate change sensitivity are limited in scope to the risks associated with breaching of the sea dikes and dunes. The calculation results show a dramatic increase of the coastal flooding risks due to breaches during the 21 st century.

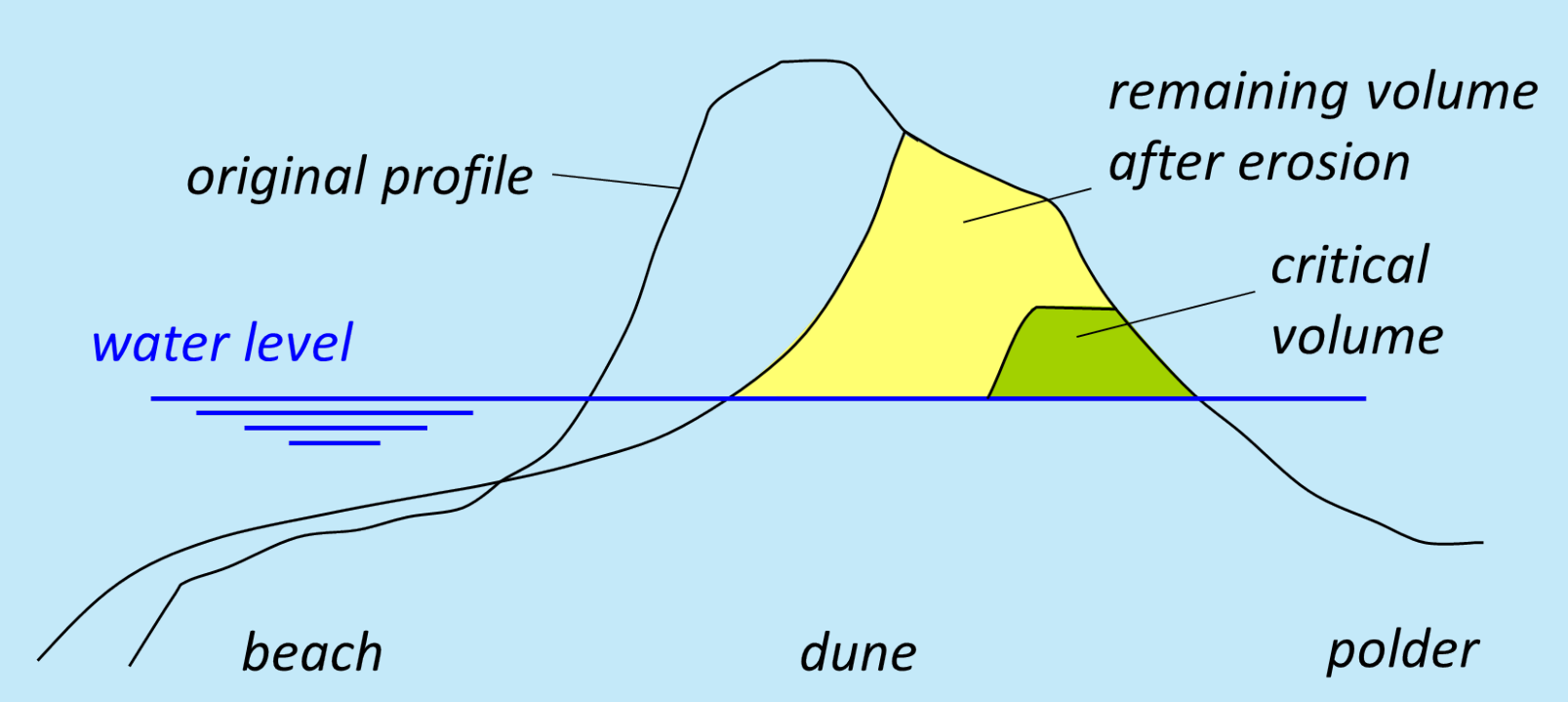

The calculation of risk is taking into account four different sources of

uncertainty (Verwaest et al 2008)

1. The unpredictability of the weather $(i)$.

2. The distribution of extreme storm surge events $(j)$

3. Limited knowledge on the behavior of the coastal defence system during extreme storms $(k)$.

4. Unknown future values of economic growth rate, population growth rate, sea level rise rate $(r, T)$.

For an average climate change scenario, with an increase of surge levels by $0.8 \mathrm{~m}$, the risks increase by a factor 10 . For the worst credible climate change scenario, with an increase of surge levels by $2.4 \mathrm{~m}$, the risks increase by a factor 100.

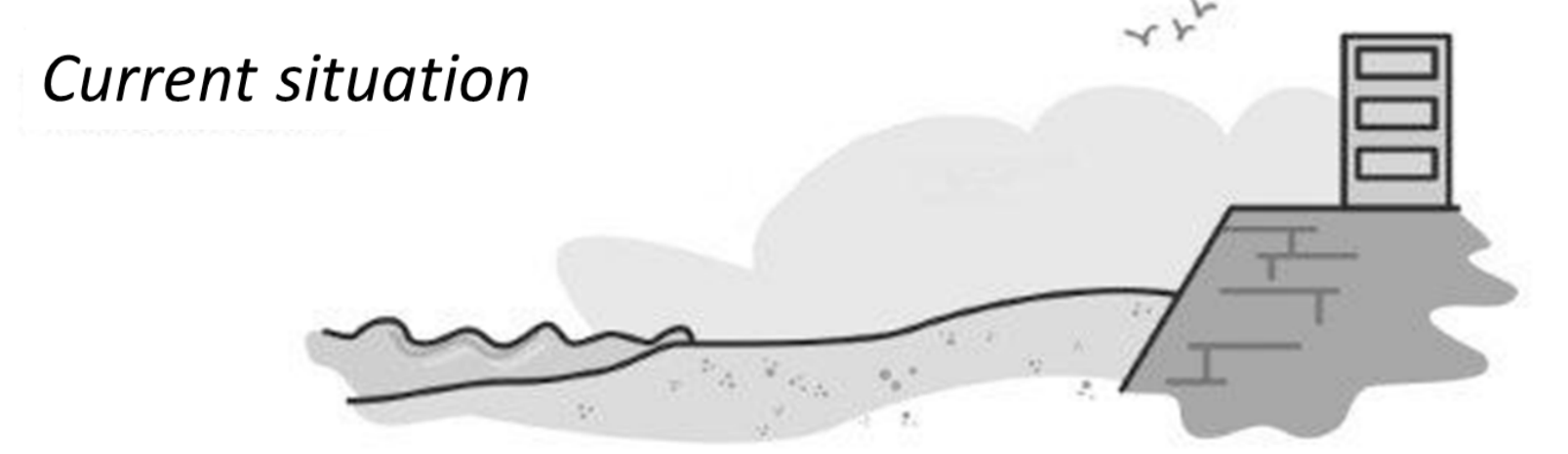

Larger dyke and beach nourishment

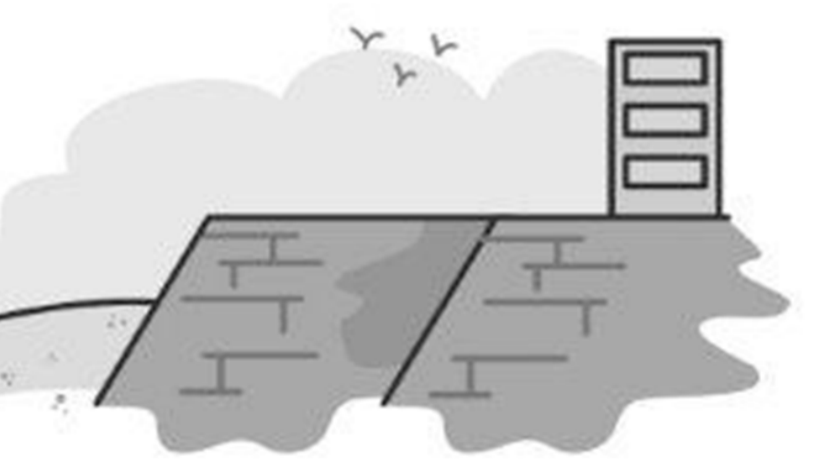

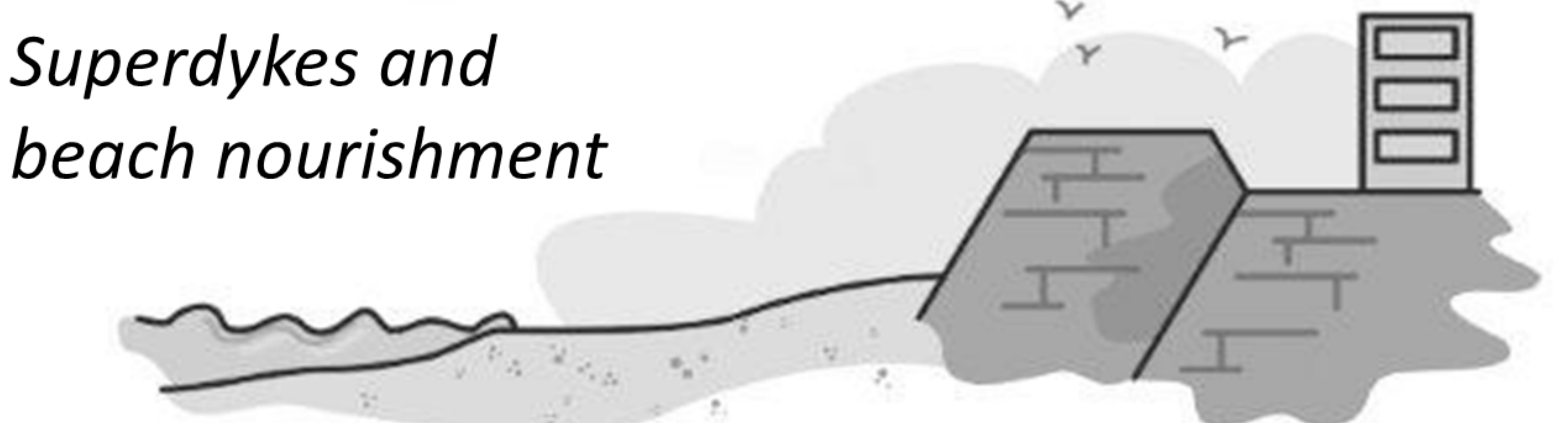

Dyke incorporated in dune

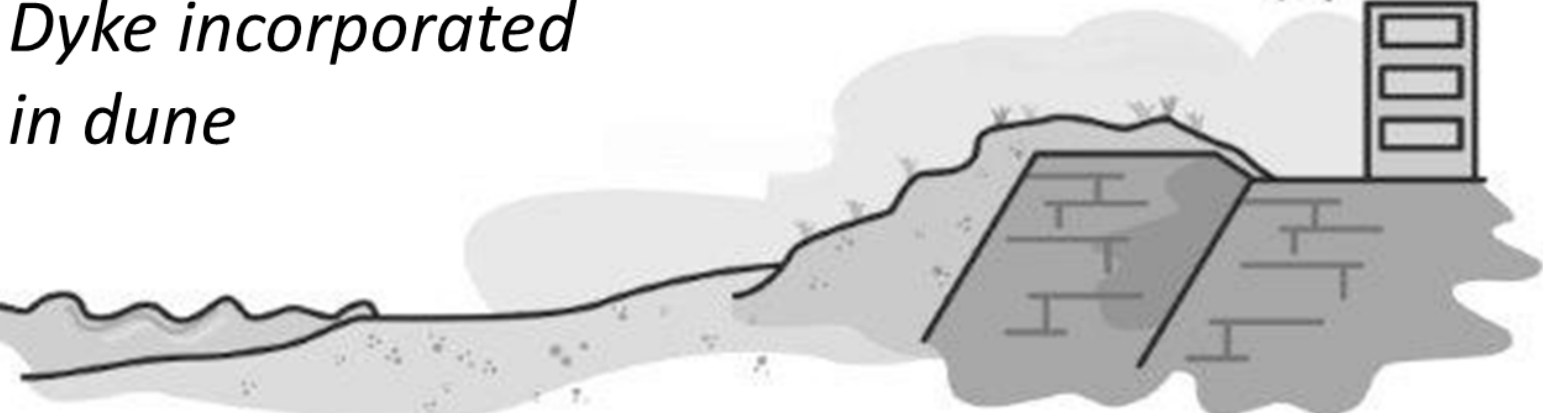

\section{References}

